\title{
5 - Objeto de aprendizagem empregado como recurso multimídia na microbiologia
}

\author{
Karlete Vania Mendes Vieira \\ Robson Pequeno de Sousa
}

\section{SciELO Books / SciELO Livros / SciELO Libros}

VIEIRA, KVM., and SOUSA, RP. Objeto de aprendizagem empregado como recurso multimídia na microbiologia. In: SOUSA, RP., et al., orgs. Teorias e práticas em tecnologias educacionais [online]. Campina Grande: EDUEPB, 2016, pp. 123-149. ISBN 978-85-7879-326-5. Available from SciELO

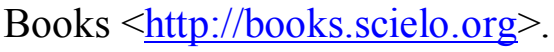

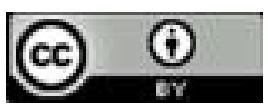

All the contents of this work, except where otherwise noted, is licensed under a Creative Commons Attribution $\underline{4.0 \text { International license. }}$

Todo o conteúdo deste trabalho, exceto quando houver ressalva, é publicado sob a licença $\underline{\text { Creative Commons }}$ Atribição 4.0. 


\section{OBJETO DE APRENDIZAGEM}

\section{EMPREGADO COMO RECURSO MULTIMÍDIA NA MICROBIOLOGIA}

\section{Karlete Vania Mendes Vieira Robson Pequeno de Sousa}

A Microbiologia é uma ciência que estuda os seres vivos microscópicos, suas características, seus comportamentos e suas aplicações. São muitos detalhes que guardam esses minúsculos seres, para transmitir esses conhecimentos aos alunos de forma dinâmica é necessário utilizar artifícios pedagógicos que promovam uma melhor compreensão e assimilação de um conteúdo tão complexo. Portanto, é fundamental, no mundo informatizado que nos encontramos hoje, tirar o máximo de proveito do arsenal tecnológico que nos é apresentado como, por exemplo, a utilização da multimídia no auxílio da transmissão do conteúdo de forma atrativa e eficaz para o aluno.

O processo de informatização da educação deve ser considerado como meio de ampliação das funções do professor, favorecendo mudanças nas condições e no processo ensino-aprendizagem. Atualmente, os sistemas multimídia interativos assumem importância crescente em todas as áreas da atividade humana que dependem de uma comunicação eficaz, incluindo a educação (RIBEIRO, 2004; MOREIRA, 1986). 
Segundo Ribeiro (2004), os avanços que se verificaram, na última década, nas tecnologias informáticas colocaram o potencial da comunicação multimídia ao alcance de qualquer pessoa: o desenvolvimento de computadores pessoais com um alto poder computacional a baixo custo permite dispor de máquinas capazes de processarem e combinarem na mesma mensagem texto, vídeo, áudio e animação. $\mathrm{E}$ as redes de comunicação são capazes de transferir rapidamente os tipos de informação permitindo comunicar instantaneamente a qualquer lugar do globo. Mas a criação de aplicações multimídia eficazes não é uma atividade que possa ser realizada ao acaso. Para se explorar as potencialidades disponibilizadas pelas tecnologias e sistemas multimídia, não basta utilizar e conhecer as ferramentas de desenvolvimento multimídia é necessário conhecer as características das tecnologias, adequar as combinações de informação visual e auditiva às mensagens que se deseja transmitir e, dotado daquele conhecimento, planejar, antes de desenvolver e produzir uma aplicação multimídia interativa.

A modernização das técnicas de ensino, no entanto, só logrará êxito se utilizada de forma crítica pelos usuários, de modo geral, visto que deverá estar associada a cada realidade educativa e fundamentada em princípios psicopedagógicos que explicitem certa concepção de ensino e aprendizagem. Em termos pedagógicos, podese afirmar que a didática de mídia ainda segue muitos conceitos da tecnologia instrucional e tradicional, visto se basear em psicologia comportamentalista (behaviorista), cujos passos básicos são: a análise de tarefa, o avanço em pequenos e progressivos passos de aprendizagem; a participação ativa do estudante; a velocidade de aprendizagem individual e a realimentação imediata do esforço (MOREIRA, 1986). 
Utilizando a multimídia, podem ser criados vários recursos pedagógicos, como por exemplo, os objetos de aprendizagem (OA) os quais são recursos digitais reutilizáveis e adequados ao uso educacional. Pode ser qualquer material digital, como textos, animação, vídeos, imagens, aplicações, páginas web de forma isolada ou em combinação, com fins educacionais. Trata-se de recursos autônomos, que podem ser utilizados como módulos de um determinado conteúdo ou como um conteúdo completo. São destinados a situações de aprendizagem tanto na modalidade a distância quanto semipresencial ou presencial. Uma das principais características deste recurso é a reusabilidade, ou seja, a possibilidade de serem incorporados a múltiplos aplicativos (WILLEY, 2000; BEHAR et al, 2007).

Os objetos de aprendizagem, como qualquer recurso, podem ser reusados para apoiar a aprendizagem e relaciona-se a materiais educacionais projetados e construídos em pequenos conjuntos com o objetivo de maximizar as situações de aprendizagem em que o OA pode ser utilizado (TAROUCO; FABRE; TAMUSIUNAS, 2003).

Nesse sentido, procurou-se desenvolver e avaliar um objeto de aprendizagem na área de Microbiologia, com recursos multimídia, destinado ao meio acadêmico ligado às ciências da saúde.

\section{INFORMÁTICA E O USO DA TECNOLOGIA NO ENSINO-APRENDIZAGEM}

Os recursos tecnológicos vieram para ficar, não são apenas as grandes corporações que estão cada vez mais investindo em tecnologia para se manter no mercado. Na educação, esta realidade não é diferente, os avanços tecnológicos requerem capacitação e treinamento por parte do docente, e a adequação da instituição ao contexto his- 
tórico, afinal estamos na era da informação, e esta nova geração de educandos buscam suas fontes de saber no mundo virtual da internet. $\mathrm{E}$ assim as diversas formas de aprender e de saber vão se propagando pelo mundo maravilhoso da internet, basta ter um computador e o acesso à internet que o indivíduo passa a deter o poder de consulta às mais variadas fontes de saberes (SOUZA apud MENDES; RUBI, 2010).

Não é segredo que os recursos tecnológicos, há muito tempo, são meios auxiliares entre o educador e o educando, podendo ser utilizados na escola desde o ingresso do educando, bastando apenas que o educador saiba utilizar o software certo na hora certa e com isso proporcionar ao educando a facilidade de absorção de determinados conteúdos, contribuindo para o seu aprendizado, sua formação e no desenvolvimento de suas habilidades e competências (COSTA, 2005).

O educando desta nova era, ao ingressar na faculdade, sua primeira curiosidade não reside mais em saber onde é a biblioteca, mas sim onde se localiza o laboratório de informática, é imperioso que as escolas, universidades e docentes se enquadrem nessas mudanças e lancem mãos dos recursos tecnológicos disponíveis, promovendo as mudanças necessárias que este novo educando requer. O docente desta era não pode ter a visão de que a tecnologia possa ser seu concorrente e sim que as ferramentas tecnológicas podem ajudá-lo a alcançar seus objetivos junto aos educando, pois os vários recursos tecnológicos podem ser utilizados como estratégias de ensino, fazendo com que o ensino-aprendizagem se dê de forma prazerosa, transformando a sala de aula num ambiente em que o tempo não seja o monstro do aluno (SOUZA apud MENDES; RUBI, 2010).

Historicamente, o modelo de ensino superior seguido pelas instituições acadêmicas brasileiras tem se caracterizado pela extrema valorização de aulas teóricas, o que torna o professor o eixo do proces- 
so de aprendizagem e o aluno um coadjuvante, a quem se oferecem informações de natureza conceitual e analítica, prontas e encerradas, existindo pouco espaço e tempo dedicados à descoberta, à criação e, até mesmo, para a reflexão (NUNES apud OKADA et al., 2007).

Há a expectativa de que, uma vez o estudante universitário formado, isto é, concluído o curso de graduação, ele passe a desempenhar uma função profissional e aplique seus conhecimentos, com criticidade e criatividade, no ambiente de trabalho, de forma prática e efetiva. No ambiente de trabalho, um cenário marcadamente empresarial, oo lugar em que o indivíduo de fato se coloca diante da ação, da realidade. O ambiente de trabalho tem, portanto, funcionado como uma extensão da "escola", em que a aprendizagem se completa com as atividades práticas. A empresa, e não a universidade tem sido o espaço da experimentação (OKADA et al, 2007).

Às instituições de ensino, incluindo as de ensino superior, cumpre empregar todos os esforços para que cada estudante possa se desenvolver plena e amplamente nos espaços da escola, diversificando as estratégias de ensino-aprendizagem, com o propósito de possibilitar uma formação integral e que atenda aos reais interesses da sociedade (NUNES apud OKADA et al., 2007).

\section{UTILIZAÇÃO DA TECNOLOGIA DE INFORMAÇÃO COMO FERRAMENTA DE SUPORTE PARA A EDUCAÇÃO DE QUALIDADE}

Acrescentaram-se as tecnologias nas universidades e nas escolas, mas, em geral, para continuar fazendo o de sempre - o professor falando e o aluno ouvindo - com uma capa de modernidade. As tecnologias são utilizadas mais para ilustrar o conteúdo do professor 
do que para criar novos desafios didáticos. Uma das reclamações de escolas e universidades é de que os alunos não aguentam mais nossa forma de dar aula. Os alunos reclamam do tédio de ficar ouvindo um professor falando na frente por horas, da rigidez dos horários, da distância entre o conteúdo das aulas e da vida.

Precisamos repensar todo o processo, reaprender a ensinar, a estar com os alunos, a orientar atividades, a definir o que vale a pena fazer para aprender, juntos ou separados. As tecnologias sozinhas não mudam a escola, mas trazem muitas possibilidades de apoio ao professor e de interação com e entre os alunos (MORAN; MASETO; BEHRENS, 2003).

A educação brasileira teve um grande avanço tecnológico, mas são necessárias algumas transformações no processo educacional para adaptar-se ao mundo atual, que cada vez exige qualidade, para receber o aluno com o novo perfil, porém a busca do conhecimento e capacitação na área tecnológica é uma exigência capaz de interferir na construção social do educando. A sociedade está mudada e o conhecimento adquirido no último século foi equivalente ao obtido durante toda a história da humanidade. Temos que nos adaptar a este dinamismo e termos noção do conhecimento geral acumulado e estarmos aptos para assimilar, em velocidade cada vez maior, conhecimentos importantes para nossas profissões (BARBOSA et al, 2010).

Nesse contexto, a tecnologia da informação e comunicação, vinculada ao processo educacional, estimulam a motivação dos educandos que passam a valorizar seus conhecimentos e produzir melhores resultados escolares. Pois construção do conhecimento é contínuo e interior, estimulado por condições exteriores criadas pelo docente. Por esse motivo, cabe a este o perfil de mediador do processo de interação com ferramentas tecnológicas para preparar suas aulas. 
Os professores deveriam adaptar seus currículos a novas realidades, deveriam usar as mesmas "armas" na transmissão do conhecimento que as mídias e ter um treinamento para tal (ARRUDA, 2004).

É evidente a necessidade de uma formação e qualificação técnica e prática que são habilidades e competências essenciais à formação dos docentes na atualidade. A tecnologia da informação é um desafio a ser vencido, é preciso que os professores tenham formação didática pedagógica, sabendo utilizar novas tecnologias da comunicação para oferecer aos educandos o conhecimento que eles precisam para que possam acompanhar a velocidade das transformações educacionais, sociais, políticas e econômicas (MENDES; RUBI, 2010).

Em vez disso, chegamos a um modelo de escola no qual os professores passam quase todo tempo dentro de salas de aula aplicando conhecimentos adquiridos, há muito tempo, e poucas vezes atualizados ou reciclados, deixando claro que um dos setores menos sensíveis ao desenvolvimento tecnológico desta sociedade é o sistema educacional. Para adaptar a educação ao mundo atual, é necessário educar para compreender melhor seu significado dentro da nossa sociedade, ajudando na sua democratização, onde cada pessoa possa exercer integralmente sua cidadania (LUCENA; FUKS, 2000).

\section{MULTIMÍDIA E EDUCAÇÃO}

As tecnologias multimídia podem ser encaradas como ferramentas que auxiliam o utilizador na divulgação de ideias, conceitos ou serviços. A forma mais comum de utilizar as tecnologias multimídia é através das aplicações multimídia, que na sua grande maioria são interativas, pois permitem que os conteúdos sejam apresentados 
de uma forma não linear em que o utilizador desempenha um papel ativo (RIBEIRO, 2004).

É possível classificar as aplicações multimídia de acordo com vários critérios, por exemplo, quanto ao tipo de utilizador, quanto ao mercado a que se destinam ou quanto à área de utilização (área de atividade humana). Quanto ao tipo de utilizador, podem, por exemplo, classificar-se em aplicações para crianças e aplicações para adultos, ou em aplicações para alunos e aplicações para professores. Se classificarmos as aplicações multimídia quanto ao mercado a que se destinam, já é possível definir classes diferentes, tais como o mercado doméstico, o mercado profissional, o mercado educativo e a administração pública.

A multimídia é uma ferramenta muito importante na comunicação e sua eficácia no aspecto educacional já está consagrada, pois possibilita a combinação das várias formas de mídia e da interatividade que ela proporciona e promove o desenvolvimento e percepção do aprendizado (BUGAY; ULBRICHT, 2000). A forma de ensinar e aprender através da multimídia é um desafio extremamente motivador, que implica em trabalhos de investigação voltados para a produção de meios e materiais e para a teorização a respeito de sua aplicação em relações educativas mediadas por esta tecnologia. A multimídia pode contribuir para um avanço qualitativo no processo de ensino -aprendizagem, pois melhora o interesse e a atenção do aluno e provoca uma melhor retenção da informação (VALENTE, 2002).

Afirma Guerra (2001) que como a multimídia ativa vários sentidos, simultaneamente, torna a informação mais redundante, oferecendo um maior poder de assimilação, além de aumentar a atenção haja vista que os apelos sensoriais são multiplicados. A multimídia é um recurso que parece ter uma vocação natural para a educação, 
uma interface multimídia bem projetada pode enriquecer o ambiente de aprendizagem e permitir que o aluno participe da construção do seu conhecimento.

\section{APRENDIZAGEM MULTIMÍDIA}

Segundo Mayer (2009), a aprendizagem multimídia ocorre quando as pessoas projetam a construção do conhecimento através da representação mental de palavras e imagens, pois elas aprendem melhor com palavras e imagens do que apenas com palavras. Ele ainda cita alguns princípios que norteiam a aprendizagem multimídia, são eles: a) O Princípio Multimídia: fala exatamente o que foi descrito acima, onde as pessoas aprendem melhor quando combinam palavras e imagens do que só palavras; b) Proximidade espacial: as palavras e imagens devem estar próximas em vez de afastadas; c) Proximidade temporal: as palavras e imagens são apresentadas simultaneamente em vez de sequencialmente; d) Coerência: se as palavras e imagens não são importantes para o tema devem ser excluídas da apresentação multimídia; e) Modalidade: utiliza animação e narração em vez de animação e texto escrito; f) Redundância: aponta maior aprendizagem através da animação e narração do que a aprendizagem através da animação, narração e texto.

\section{OBJETO DE APRENDIZAGEM COMO INSTRUMENTO DE ENSINO-APRENDIZAGEM}

Segundo Willey (2000), os objetos de aprendizagem são recursos digitais reutilizáveis e adequados ao uso educacional. Num contexto mais atual, Behar et al (2007) definem objeto de aprendiza- 
gem como qualquer material digital, como textos, animação, vídeos, imagens, aplicações, páginas web de forma isolada ou em combinação, com fins educacionais. Trata-se de recursos autônomos, que podem ser utilizados como módulos de um determinado conteúdo ou como um conteúdo completo. São destinados a situações de aprendizagem tanto na modalidade a distância quanto semipresencial ou presencial. Uma das principais características deste recurso é a reusabilidade, ou seja, a possibilidade de serem incorporados a múltiplos aplicativos. Um mesmo objeto pode ter diferentes usos, seu conteúdo pode ser reestruturado ou reagregado, e ainda ter uma interface modificada para ser adaptada a outros módulos. Todas essas ações podem ocorrer de forma independente ou conciliada com outros objetos, considerando sempre os objetos a serem alcançados com o público alvo de (re) utilização do OA.

Os autores Tarouco; Fabre; Tamusiunas (2003) complementam definindo os objetos educacionais ou objetos de aprendizagem como qualquer recurso, suplementar ao processo de aprendizagem, que pode ser reusado para apoiar a aprendizagem. Dessa forma, a expressão "objeto educacional"relaciona-se a materiais educacionais projetados e construídos em pequenos conjuntos com o objetivo de maximizar as situações de aprendizagem em que o OA pode ser utilizado.

Betio; Martins (2004), Tarouco; Fabre; Tamusiunas (2003) ressaltam que a reusabilidade não é a única característica de um objeto. Destacam-se também acessibilidade, interoperabilidade, durabilidade e customização. A acessibilidade corresponde à possibilidade de acesso remoto aos recursos educacionais através de um repositório. A interoperabilidade potencializa a reutilização dos objetos, na medida em que visa à articulação/comunicação de materiais em diferentes 
plataformas e ferramentas. Já o critério de durabilidade aponta para a garantia do uso do recurso educacional, mesmo quando a base tecnológica em que ele foi desenvolvido sofreu mudanças. Tais considerações evitam a reconstrução ou a reprogramação do objeto em questão. E finalmente, a customização refere-se à flexibilidade e à adaptação do material a diferentes níveis de ensino, incluindo nessa perspectiva a construção de novos conteúdos a partir da base que compõe o projeto inicial.

Os repositórios são espaços remotos onde os objetos são armazenados, obedecendo a uma lógica de identificação para que ele possa ser localizado a partir de buscas por tema, nível de dificuldade, autor ou pela relação com demais objetos. Os repositórios de objetos de aprendizagem, como a Coletânea de Entidades de Suporte ao uso de Tecnologia na Aprendizagem (CESTA) ${ }^{1}$, são sistemas de catalogação que permitem a publicação e a reutilização desses OAs por parte de qualquer usuário em qualquer curso. Também possibilitam a utilização dos objetos como fonte de pesquisa e de referência para que outros educadores organizem suas aulas, disponibilizem aos alunos ou os avaliem.

Alguns tipos de objetos de aprendizagem são bastante óbvios e não necessitam de maiores esclarecimentos como textos, hipertextos, vídeos, imagens. Contudo, há uma categoria de objetos que tem um potencial educacional extremamente rico e diversificado: as simulações (por exemplo, jogos interativos). Nesse caso, é interessante pensar que em alguns momentos é o uso do objeto - os parâmetros testados, as decisões tomadas, as configurações feitas, etc. - que demonstra o processo de aprendizagem e o domínio sobre certo assunto (OKADA et al, 2007).

1 Disponível em: http//www.cinted.ufrgs.br/CESTA/ 
Existem diversos tipos de objetos de aprendizagem. Em geral, quem cria um objeto tem alguma finalidade em mente e alguma concepção de ensino-aprendizagem. A finalidade pode ser a de introduzir um assunto de maneira contextualizada, de criar uma oportunidade para o uso de um conhecimento já adquirido, de demonstrar algum conceito complexo, de ressaltar interligações entre vários conceitos, de induzir certo tipo de pensamento ou comportamento no usuário, de ajudar num processo de educação, de avaliar o grau de conhecimento do usuário sobre certo assunto ou habilidade, etc. A maneira como isso é feito depende da concepção de ensino e aprendizagem de quem o criou: o aluno pode vir mais ou menos organizado e estruturado, a navegação pode ser obrigatória ou optativa, pode ser linear ou ter níveis de complexidade para satisfazer diferentes tipos de público, pode ou não estimular a metacognição, etc. (OKADA et al, 2007).

Um professor que escolhe um objeto para usar como estratégia de ensino e aprendizagem deve ter em mente a finalidade para a qual ele foi proposto e qual o estágio de desenvolvimento de seus alunos. O professor tem ou deveria ter o papel de arquiteto e designer da aprendizagem. É ele quem consegue criar caminhos cognitivos interessantes, desafiadores e significativos para seus alunos. Uma boa oferta de recursos educacionais - objetos de aprendizagem, especialistas, excursões a campo, experiências em laboratório, etc. - permite a criação desses caminhos segundo a visão educacional do professor. Alguns autores têm obtido sucesso em suas pesquisas com aplicações de objetos de aprendizagem utilizando a multimídia em diferentes áreas, na Geografia e Matemática, Soares (2008) desenvolveu um software educacional para ser utilizado no ensino-aprendizado em topografia e obteve êxito em sua aplicação, levando os alunos a com- 
preenderem melhor o conteúdo antes tão distante da realidade dos mesmos. Na área de saúde Illera (apud Mishra, Sharma, 2005) cita em seu estudo o uso de um software na área de saúde, onde desenvolveu um CD com informações sobre a AIDS como o que é, como se adquire, quais os riscos e como as pessoas devem se prevenir, os alunos tiveram ótimo rendimento no aprendizado. Zem-Mascarenhas e Cassiani (2001) também avaliaram um software educacional para o ensino de enfermagem pediátrica, a maioria dos alunos avaliou de forma positiva tal objeto de aprendizagem. Na área de Engenharia Civil, Assis (2002) encontrou satisfação dos alunos quando utilizou os recursos multimídia no ensino de estruturas de concreto armado e protendido.

\section{ASPECTOS RELEVANTES PARA O DESENVOLVIMENTO DE OBJETOS DE APRENDIZAGEM}

Considerando as características pertinentes aos OAs, notase que o planejamento e a construção deles podem requerer do autor a apropriação de temas de diferentes áreas do conhecimento. Assim, considera-se relevante a formação de um grupo interdisciplinar para construção de um material educacional digital que alcance as características pertinentes ao objeto. A troca de ideias e de informações e o confronto de diferentes perspectivas acerca da construção do material são as principais vantagens de um trabalho cooperativo coeso e consistente. Para o desenvolvimento de um material de boa qualidade, é necessário ter conhecimento de usabilidade, interface, linguagem de programação/softwares que permitam a implementação do material e a publicação em repositórios quando for o caso. Também é necessário ter noções precisas do conteúdo em si para poder elaborar o material 
de apoio e as atividades propostas. O ideal é contar com uma equipe interdisciplinar (BEHAR et al, 2009).

Afirmam Betio, Martins (2004); Prata; Nascimento (2007), Silva; Fernandes (2007); Tarouco; Fabre; Tamusiunas (2003) que o educador precisa estar atento a alguns aspectos relevantes ao desenvolverem um OA;

Primeiro, os professores devem conhecer muito bem os conteúdos a serem apresentados, pois, caso contrário, podem permitir que conceitos errôneos estejam presentes no material, ou possam dar margem a interpretações que não estejam de acordo com o mundo real. Esses desvios podem ser derivados de uma programação não estruturada ou de definições empíricas do próprio programador, quando o professor não estiver executando essa função.

O professor deve conhecer as possibilidades ou recursos de programação, pois o objeto deve atender ao modelo pedagógico teorizado pelo educador; pois de nada vale desenvolver um objeto que não contemple os ideais propostos.

O professor deve também ter conhecimentos sobre o potencial do aplicativo escolhido para desenvolver o objeto, pois este pode permitir a implantação de recursos que modelem a teoria pedagógica, mas não atendam as necessidades totais dos educandos. Os estudos sobre a modelagem de um OA devem envolver um grupo inter e multi disciplinar que possa realmente colaborar na construção de um objeto robusto em termos de operacionalidade, flexível em ambientes, consistente em conteúdos aplicáveis às teorias educacionais subjacentes, adaptável às dos alunos.

O professor deve ser conhecedor das condições de aprendizagem de seus alunos, dos níveis de conhecimentos já adquiridos 
sobre o tema a ser desenvolvido e do uso de recursos computacionais, além de condições socioeconômicas e culturais.

Destaca-se ainda que, para o desenvolvimento de OAs, é importante considerar tanto os aspectos educacionais quanto estéticos e tecnológicos. Dessa forma, partindo da análise dos aspectos já mencionados, busca-se oferecer ao usuário OA de fácil navegação e agradável experiência estética de forma que os anseios educacionais possam ser atendidos.

O modelo para o planejamento sistemático de projeto multimídia baseia-se no princípio DDD-E segundo Ivers e Barron (2006) que consiste nas etapas Decide, Design, Development e Evaluate, onde a primeira etapa Decide determina a meta do projeto, desenvolve o Brainstorm "mapa conceitual", realiza a pesquisa e planeja as atividades para professores e alunos; Design: determina a estrutura do programa e sua implementação, desenhando os fluxogramas, projetando as telas específicas e criando os "storyboards"; a etapa de Develop: cria elementos de mídia, coleta e facilita a lição através do áudio, vídeo, gráficos, animações, programas de autoria; e por fim a fase Evaluate (avaliação): reflete sobre o projeto, perspectiva futura e desempenho do aluno, necessária para validação da aplicação educativa.

\section{O PERCURSO: OBJETO DE APRENDIZAGEM NO ENSINO DA MICROBIOLOGIA}

A presente pesquisa propôs melhorar a aprendizagem do conteúdo de Genética bacteriana com uma turma de alunos que cursaram o segundo ano de Odontologia da Universidade Estadual da Paraíba, durante os períodos de 2010.1 e 2010.2, através da aplicação de um Objeto de Aprendizagem. A turma era composta de dezesseis 
(16) alunos, todos cursaram a disciplina de Microbiologia Básica no período 2010.1. Entretanto, a análise final foi realizada com catorze (14) alunos, ou seja, aqueles que compareceram para a aplicação e avaliação do Objeto de Aprendizagem (OA).

O desenvolvimento do OA com os tópicos considerados básicos para entendimento do conteúdo foi baseado nos princípios da multimídia, seguindo o modelo para projetos multimídia na educação, o DDD-E(Decide, Design, Develop, Evaluate).

A primeira fase - Decide - que se refere à fase inicial do desenvolvimento, foi composta do Mapa Conceitual do conteúdo com os principais pontos teóricos a serem abordados durante o OA.

A segunda fase - Design - esteve relacionada com o conteúdo, e a estruturação inicial da aplicação foi elaborada através do Mapa Navegacional, do Mapa de Cenário e do Roteiro lógico do conteúdo a ser seguido. O Mapa Navegacional apresentou como seria a sequência dos pontos teóricos ao longo do OA, divididos em Telas, e o Mapa de Cenário, o ambiente ilustrativo, onde acontece toda apresentação do OA.

Na terceira fase - Develop - que se referiu ao desenvolvimento propriamente dito do OA, foram utilizados alguns softwares do tipo proprietários e outros livres, nesse sentido, utilizou-se um software para animação: Macromedia Flash (proprietário); um software de edição de imagens: Gimp (livre); três softwares de edição de áudio: Audacity; DVDVideoSoft Free Studio, AVIReComp (ambos softwares freeware); além de um software de conversão e download de vídeos: Atube Catcher (totalmente freeware). Esta fase foi desenvolvida por um aluno do último ano de Licenciatura da Computação da Universidade Estadual da Paraíba.

A última fase - Evaluate - fase de avaliação foi realizada após confecção, revisão e teste do OA o qual foi aplicado no final do 
período 2010.2, em sala de aula, e exposto em datashow para todos os alunos de uma única vez no horário de duas aulas consecutivas. O conteúdo do OA foi dividido em três etapas, após cada etapa, havia um exercício relacionado, totalizando três exercícios. Ao final do OA, foram aplicados dois questionários para avaliação do mesmo.

Foram aplicados três exercícios, os quais foram respondidos sequencialmente, no momento em que os mesmos iam sendo apresentados durante o decorrer do OA. Cada aluno recebeu as mesmas questões apresentadas no OA de forma digitadas e impressas, as quais eram respondidas imediatamente à sua exposição no datashow durante a apresentação do OA, o objetivo destes exercícios foi saber se estava havendo assimilação imediata do conteúdo apresentado. Ao final da apresentação do OA, dois tipos de questionários foram aplicados aos alunos com a finalidade de avaliar a função educacional do OA e sua diferença com relação à aula convencional.

Para análise geral, foram utilizadas as notas atribuídas a cada resposta da escala de Likert, onde as mesmas variaram de 1 a 5 . A partir dessas notas, foi determinada a média dos pontos, conforme metodologia descrita por Berenson e Levine (1992), a qual foi adaptada para a seguinte fórmula:

$$
M P=\frac{(P 1 . N a)+(P 2 . N a)+(P 3 . N a)+(P 4 . N a)+(P 5 . N a)}{N T a}
$$

Em que:

MP: Média dos pontos

P1, P2, P3, P4 e P5: Pontos referentes às notas atribuídas às respostas da escala de Likert, ou seja, 1, 2, 3, 4 e 5, respectivamente.

Na: Número de alunos que atribuíram cada ponto individualmente da escala de Likert.

NTa: Número total de alunos envolvidos na pesquisa. 


\section{APRESENTAÇÃO DOS RESULTADOS}

O primeiro módulo do OA foi relacionado aos constituintes básicos da genética bacteriana; ao seu término, foram aplicadas quatro questões. Conforme os resultados da Figura 1, percebe-se que a maioria deles (64\% ) acertou todas as questões apresentadas no OA e $29 \%$ só erraram apenas uma questão, isso indica que houve boa assimilação do conteúdo inicial por parte dos alunos. Esse dado é importante, haja vista que o entendimento desse conteúdo é fundamental para compreender os demais conteúdos apresentados nos módulos seguintes.

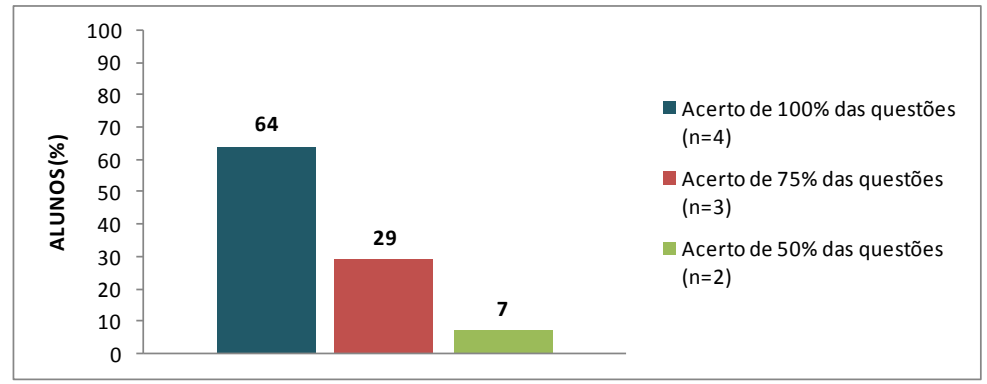

FIGURA 1 - Percentual de acerto nas quatro questões aplicadas ao final do primeiro módulo do $\mathrm{OA}$

FONTE - Os autores

O segundo módulo abordou a síntese protéica, as etapas necessárias para que uma proteína seja formada no interior da bactéria e como essas etapas acontecem. O segundo questionário foi composto de cinco questões e o percentual de acerto das mesmas pelos alunos está apresentado na Figura 2. Igualmente ao primeiro módulo, o número percentual de alunos que acertaram todas as questões foi $64 \%$ e o percentual restante errou apenas uma questão, indicando um aprendizado satisfatório do conteúdo abordado. 


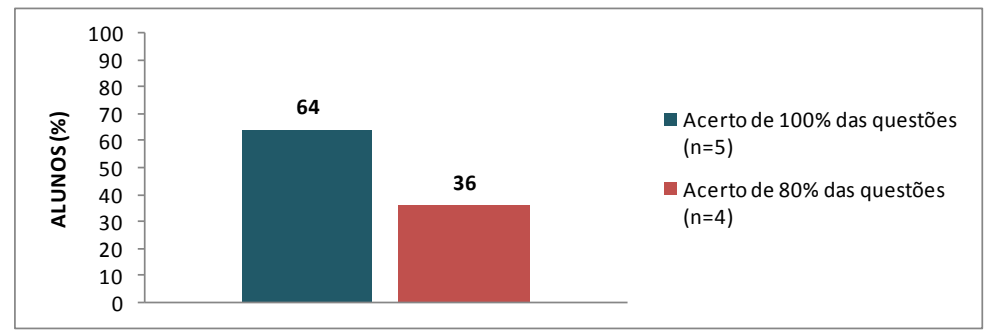

FIGURA 2 - Percentual de acerto nas cinco questões aplicadas ao final do segundo módulo do OA

FONTE - Os autores

Finalmente, foi avaliado o último módulo, este com um conteúdo mais extenso e complexo que envolve os mecanismos de transferência de genes entre as bactérias. Foram apresentadas quatro questões e os percentuais de acerto das mesmas pelos alunos encontram-se na Figura 3. Apesar da complexidade e da quantidade de conteúdo, o percentual de alunos que acertaram todas as questões foi o maior encontrado com aproximadamente $80 \%$. Este dado tem relevância haja vista que esse assunto é de difícil compreensão por parte dos alunos, quando ministrado através de aulas convencionais apontando uma eficácia deste $\mathrm{OA}$ provavelmente pela forma didática atrativa e interativa em que é apresentado, principalmente pela presença das ilustrações, dos vídeos e dos exercícios. 


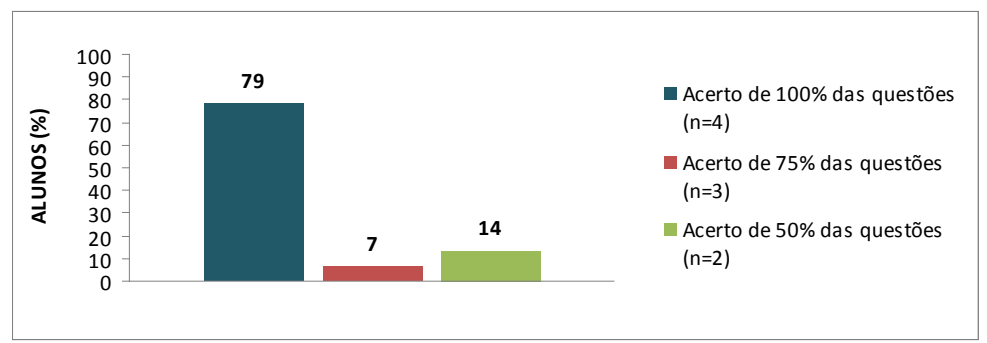

FIGURA 3 - Percentual de acerto nas quatro questões aplicadas ao final do terceiro módulo do OA

FONTE - Os autores

\section{RESULTADOS DAS AVALIAÇÕES SOBRE O OBJETO DE APRENDIZAGEM}

Inicialmente, gostaríamos de saber se o OA apresentou uma maior interação com o aluno do que a aula expositiva convencional e a grande maioria (57\% ) concordou plenamente com essa afirmativa (Figura 4). Quando calculados os pontos, verificou-se que os alunos atribuíram um valor de 4,4 para essa variável. Dentre as diferentes concepções que visam interpretar o funcionamento da aprendizagem do homem, Fenner (2000) cita a concepção interacionista, segundo a qual, o homem constrói seus conhecimentos pela constante interação com o meio, combinando sua aptidão inata de aprender com os estímulos de realimentação, recebidos do meio ambiente onde realiza suas experiências, visando a sua sobrevivência. Dessa forma, quanto maior a interação com o material multimídia disponível, maior e melhor será o aprendizado do aluno ou do professor. 


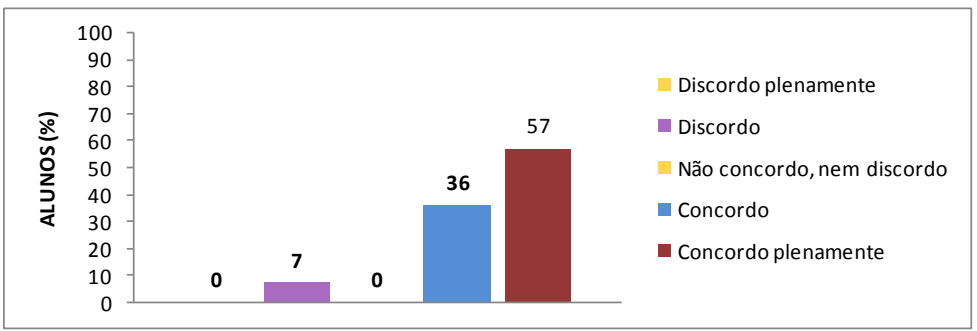

FIGURA 4 - Avaliação quanto ao OA apresentar melhor interação com o aluno do que a aula expositiva convencional

FONTE - Os autores

A maioria dos alunos (72\% ) concordou plenamente que o OA foi mais didático do que a aula convencional, embora pequeno percentual discordou ( $14 \%$ ) ou discordou plenamente (7\% ) conforme apresenta a Figura 5. O total de pontos atingidos foi de 4,2. As vantagens da multimídia estão incentivando o desenvolvimento de sistemas ou aplicações multimídia voltados para o ensino. Porém, cabe salientar que cada mídia é mais adequada para transmitir um tipo de informação; assim, como a multimídia trabalha com um conjunto delas, há uma sinergia no sentido de que uma mídia complementa a outra no processo de transmissão de informação (GUERRA, 2001).

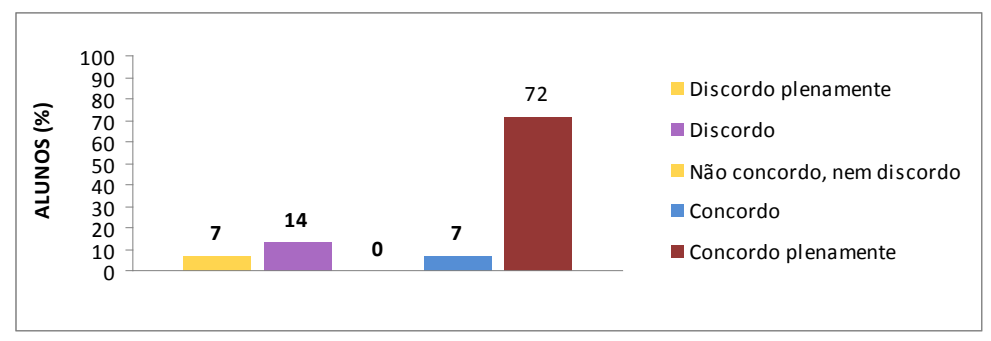

FIGURA 5 - Avaliação quanto ao OA ser mais didático do que a aula expositiva convencional

FONTE - Os autores 
A Figura 6 apresenta, de forma clara, que a grande maioria $(79 \%$ ) dos alunos concordou plenamente que as animações gráficas proporcionaram um melhor entendimento do conteúdo quando comparado com a aula expositiva convencional. Neste parâmetro, o total de pontos foi 4,7. Este dado apresenta a importância do vídeo no processo de ensino-aprendizagem haja vista que este meio multimídia é capaz de acionar sentidos do nosso corpo, como a visão e audição, interligando-os com o movimento das imagens, tornando a aula mais atrativa e dinâmica. Nascimento e Bastos (1996) afirmam que ao misturar o aspecto interativo do computador com o poder audiovisual dos vídeos, a multimídia torna-se um poderoso método de comunicação que possibilita ao professor atingir seus objetivos junto aos alunos, de maneira atrativa e eficaz, despertando maior interesse e motivação.

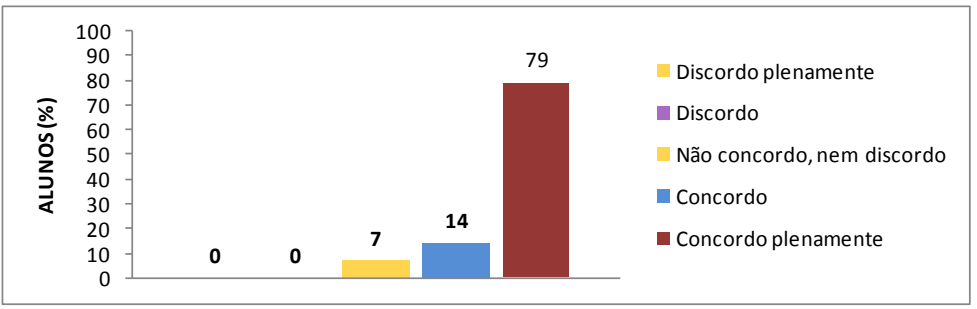

FIGURA 6 - Avaliação quanto às animações gráficas do OA proporcionarem melhor compreensão do conteúdo do que a aula expositiva convenciona FONTE - Os autores

Quanto ao aprendizado, 50\% dos alunos concordam plenamente que o mesmo foi mais rápido com o uso do $\mathrm{OA}$ em comparação com aquele obtido na aula convencional, um total de $36 \%$ concorda com essa afirmativa e $14 \%$ não concordam nem discordam. Os resultados estão apresentados na Figura 7. Essa rapidez de aprendizado com o OA recebeu uma avaliação de 4,4 pontos de acordo com a escala 
de Likert. Os dados de Soares (2008) concordam tanto no percentual quanto na pontuação no que se refere a esse item.

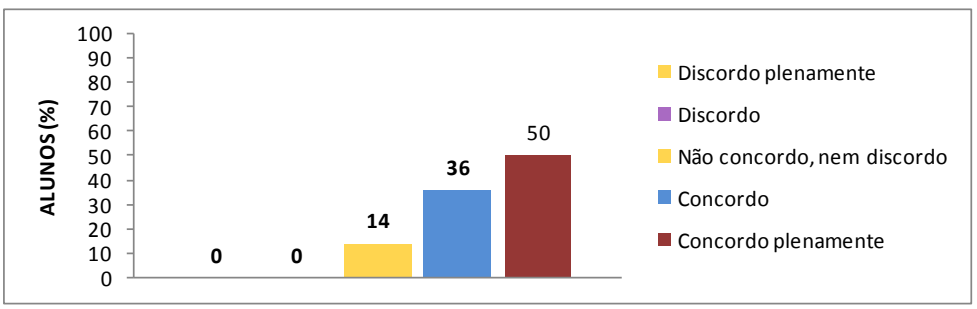

FIGURA 7 - Avaliação quanto ao aprendizado ser mais rápido com o OA quando comparado à aula expositiva convencional FONTE - Os autores

A maioria dos alunos (64\% ) concorda plenamente que a aula teórica de Microbiologia referente ao assunto Genética Bacteriana se tornou mais atrativa com o OA (Figura 8). Verificou-se um total de 4,6 pontos para essa característica.

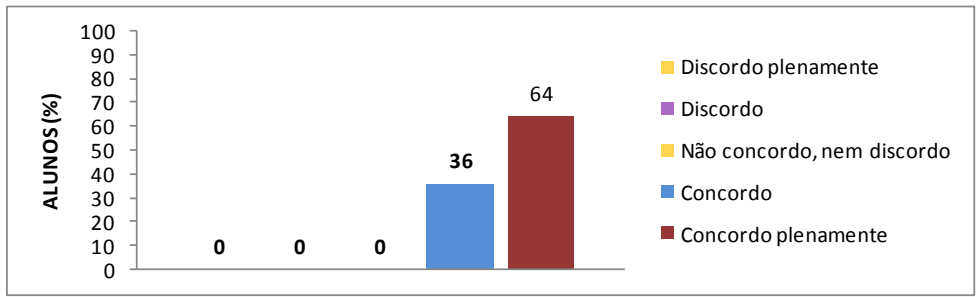

FIGURA 8 - Avaliação quanto ao OA tornar as aulas teóricas mais atrativas FONTE - Os autores

Com relação à afirmativa de que o OA é suficiente para substituir a aula, houve diversidade de opiniões. Porém $43 \%$ dos alunos concordam plenamente com essa afirmativa, $29 \%$ apenas concor- 
dam, 7\% não concordam nem discordam e 21\% discordam(Figura 9). Neste quesito, foi verificada uma nota de 3,9 pontos.

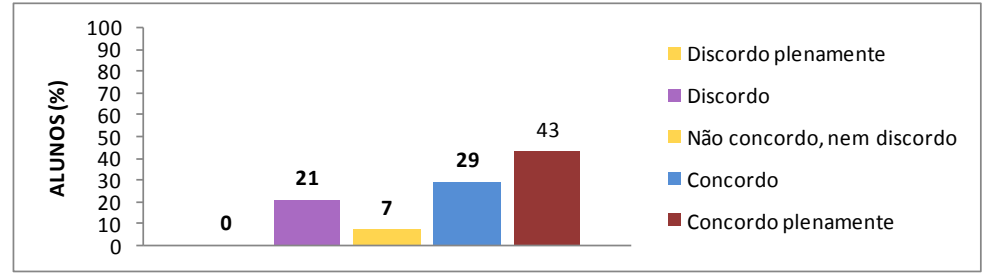

FIGURA 9 - Avaliação quanto ao OA ser suficiente para substituir a aula expositiva convencional

FONTE - Os autores

\section{CONSIDERAÇÕES FINAIS}

Por ser um poderoso método de comunicação, a multimídia tem possibilitado ao professor atingir seus objetivos de ensino junto aos alunos, de maneira eficaz e atrativa, despertando maior interesse e motivação. Baseado nos resultados obtidos, segundo avaliação dos estudantes, pode-se afirmar que o sistema multimídia aqui avaliado pode ser utilizado como recurso didático no ensino e aprendizado da Microbiologia, de maneira satisfatória.

O Objeto de Aprendizagem aplicado também demonstrou proporcionar uma boa assimilação do conteúdo através dos índices de acertos observados nos exercícios aplicados após cada módulo.

A utilização desse tipo de recurso computacional, como ferramenta de auxílio no processo ensino-aprendizagem e sua implementação nos vários segmentos educacionais, inclusive no ensino superior, vem tornando-se necessária para atrair a atenção dos alunos 
e os tornarem mais motivados a aprenderem determinados conteúdos que, por vezes, são enfadonhos e de difícil entendimento.

\section{REFERENCIAS}

ARRUDA, E. Ciberprofessor: novas tecnologias, ensino e trabalho docente. Belo Horizonte: Autêntica, 2004.

ASSIS, W. S. Utilização de recursos multimídia no ensino de concreto armado e protendido. 2002. São Paulo-SP. Dissertação de Mestrado em Engenharia, 121p. Escola politécnica da Universidade de São Paulo.

BUGAY, E. L.; ULBRICHIT, V. R. Hipermídia. São Paulo: Visual Books, 2000.

COSTA, C. Educação, imagem e média. São Paulo: Cortez, 2005.

GUERRA, J.H.L. Utilização do computador no processo de ensino-aprendizagem: uma ampliação em planejamento e controle de produção. 159f. Dissertação (Mestrado em Engenharia de Produção). Universidade de São Paulo, São Carlos, 2001.

ILLERA, J. R. Interactive multimídia and AIDS prevention: A case study. In. MISHRA, S; SHARMA, R. C. Interactive multimedia in education and training. Hershey, PA: Idea Group, 2005, pp.271-288.

IVERS, K. S.; BARRON, A. E. Multimedia Projects In Education: designing, producing and Assessing. Third Edition, USA: Libraries. 
LUCENA, C.; FUKS, H. A educação na era da internet. Rio de Janeiro: Clube do Futuro, 2000.

MENDES, M.; RUBI, R. C. Internet, multimídia \& educação. Pará de Minas, MG: Virtualbooks, 2010.

MORAN, J. M.; MASETTO, M.; BEHRENS, M. Novas tecnologias e mediação pedagógica. 7. ed. São Paulo-SP: Papirus, 2003.

MOREIRA, M. O uso do computador na Educação: pressupostos psicopedagógicos. Educação em Revista, n.4, p.13-17. Belo Horizonte, 1986.

OKADA, A. L. P. et. al. Tecnologia educacional e aprendizagem: o uso dos recursos digitais. São Paulo: Livro Pronto, 2007.

RIBEIRO, N. Multimédia e tecnologias interactivas. Lisboa: FCA Editora de Informática, 2004.

SOARES, C.S. Desenvolvimento e avaliação de sistema multimídia para o ensino e aprendizagem em topografia. 39f. Monografia (Especialização em Novas Tecnologias na Educação). Universidade Estadual da Paraíba, Campina Grande, 2008.

ZEM-MASCARENHAS, S. H; CASSIANI, S. H. B. Desenvolvimento e avaliação de um software educacional para o desenvolvimento de enfermagem pediátrica. Revista Latino-Am. Enfermagem, v.9, n.6, p.13-18, 2001. 
WILLEY, D. A. Connecting learning objects to instructional design theory: A definition, a metaphor, and a taxonomy. Digital Learning Environments Research Group, 2000. 